NASA/TM-2012-217691

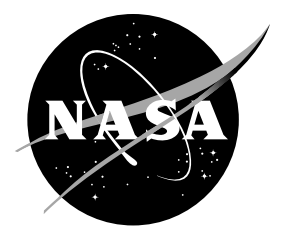

\title{
Dwell Notch Low Cycle Fatigue Behavior of a Powder Metallurgy Nickel Disk Alloy
}

J. Telesman and T.P. Gabb

Glenn Research Center, Cleveland, Ohio

Y. Yamada

Ohio Aerospace Institute, Brook Park, Ohio

L.J. Ghosn

Glenn Research Center, Cleveland, Ohio

D. Hornbach and N. Jayaraman

Lambda Research, Inc., Cincinnati, Ohio 


\section{NASA STI Program . . . in Profile}

Since its founding, NASA has been dedicated to the advancement of aeronautics and space science. The NASA Scientific and Technical Information (STI) program plays a key part in helping NASA maintain this important role.

The NASA STI Program operates under the auspices of the Agency Chief Information Officer. It collects, organizes, provides for archiving, and disseminates NASA's STI. The NASA STI program provides access to the NASA Aeronautics and Space Database and its public interface, the NASA Technical Reports Server, thus providing one of the largest collections of aeronautical and space science STI in the world. Results are published in both non-NASA channels and by NASA in the NASA STI Report Series, which includes the following report types:

- TECHNICAL PUBLICATION. Reports of completed research or a major significant phase of research that present the results of NASA programs and include extensive data or theoretical analysis. Includes compilations of significant scientific and technical data and information deemed to be of continuing reference value. NASA counterpart of peer-reviewed formal professional papers but has less stringent limitations on manuscript length and extent of graphic presentations.

- TECHNICAL MEMORANDUM. Scientific and technical findings that are preliminary or of specialized interest, e.g., quick release reports, working papers, and bibliographies that contain minimal annotation. Does not contain extensive analysis.

- CONTRACTOR REPORT. Scientific and technical findings by NASA-sponsored contractors and grantees.
- CONFERENCE PUBLICATION. Collected papers from scientific and technical conferences, symposia, seminars, or other meetings sponsored or cosponsored by NASA.

- SPECIAL PUBLICATION. Scientific, technical, or historical information from NASA programs, projects, and missions, often concerned with subjects having substantial public interest.

- TECHNICAL TRANSLATION. Englishlanguage translations of foreign scientific and technical material pertinent to NASA's mission.

Specialized services also include creating custom thesauri, building customized databases, organizing and publishing research results.

For more information about the NASA STI program, see the following:

- Access the NASA STI program home page at http://www.sti.nasa.gov

- E-mail your question to help@sti.nasa.gov

- Fax your question to the NASA STI Information Desk at 443-757-5803

- Phone the NASA STI Information Desk at 443-757-5802

- Write to: STI Information Desk NASA Center for AeroSpace Information 7115 Standard Drive Hanover, MD 21076-1320 
NASA/TM-2012-217691

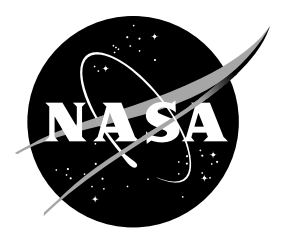

\title{
Dwell Notch Low Cycle Fatigue Behavior of a Powder Metallurgy Nickel Disk Alloy
}

\author{
J. Telesman and T.P. Gabb \\ Glenn Research Center, Cleveland, Ohio \\ Y. Yamada \\ Ohio Aerospace Institute, Brook Park, Ohio \\ L.J. Ghosn \\ Glenn Research Center, Cleveland, Ohio \\ D. Hornbach and N. Jayaraman \\ Lambda Research, Inc., Cincinnati, Ohio
}

Prepared for the

Superalloys 2012: The 12th International Symposium on Superalloys

sponsored by the The Minerals, Metals \& Materials Society (TMS)

Champion, Pennsylvania, September 9-13, 2012

National Aeronautics and

Space Administration

Glenn Research Center

Cleveland, Ohio 44135 


\section{Acknowledgments}

The authors wish to acknowledge the support of the NASA Aviation Safety program. The assistance of Rick Rogers and David Hull in performing x-ray diffraction analysis and the FIB-SEM microscopy work is gratefully acknowledged. The authors are particularly grateful for advice and assistance of Sue Draper, Chantal Sudbrack, and Pete Kantzos.

Level of Review: This material has been technically reviewed by technical management.

Available from

NASA Center for Aerospace Information 7115 Standard Drive

Hanover, MD 21076-1320
National Technical Information Service 5301 Shawnee Road Alexandria, VA 22312

Available electronically at http://www.sti.nasa.gov 


\title{
Dwell Notch Low Cycle Fatigue Behavior of a Powder Metallurgy Nickel Disk Alloy
}

\author{
J. Telesman and T.P. Gabb \\ National Aeronautics and Space Administration \\ Glenn Research Center \\ Cleveland, Ohio 44135 \\ Y. Yamada \\ Ohio Aerospace Institute \\ Brook Park, Ohio 44142 \\ L.J. Ghosn \\ National Aeronautics and Space Administration \\ Glenn Research Center \\ Cleveland, Ohio 44135 \\ D. Hornbach and N. Jayaraman \\ Lambda Research, Inc. \\ Cincinnati, Ohio 45227
}

\begin{abstract}
A study was conducted to determine the processes which govern dwell notch low cycle fatigue (NLCF) behavior of a powder metallurgy $(\mathrm{P} / \mathrm{M}) \mathrm{ME} 3$ disk superalloy. The emphasis was placed on the environmentally driven mechanisms which may embrittle the highly stressed notch surface regions and reduce NLCF life. In conjunction with the environmentally driven notch surface degradation processes, the visco-plastic driven mechanisms which can significantly change the notch root stresses were also considered.

Dwell notch low cycle fatigue testing was performed in air and vacuum on a ME3 $\mathrm{P} / \mathrm{M}$ disk alloy specimens heat treated using either a fast or a slow cooling rate from the solutioning treatment. It was shown that dwells at the minimum stress typically produced a greater life debit than the dwells applied at the maximum stress, especially for the slow cooled heat treatment. Two different environmentally driven failure mechanisms were identified as the root cause of early crack initiation in the min dwell tests. Both of these failure mechanisms produced mostly a transgranular crack initiation failure mode and yet still resulted in low NLCF fatigue lives. The lack of stress relaxation during the min dwell tests produced higher notch root stresses which caused early crack initiation and premature failure when combined with the environmentally driven surface degradation mechanisms.

The importance of environmental degradation mechanisms was further highlighted by vacuum dwell NLCF tests which resulted in considerably longer NLCF lives, especially for the min dwell tests.
\end{abstract}

\section{Introduction}

A new generation of powder metallurgy (P/M) disk superalloys has been designed for higher engine operating temperatures by improvement of their strength and creep resistance. However, the increased strength and creep resistance of these alloys may also increase their notch sensitivity to fatigue loading and thus have a profound effect on the notched low cycle fatigue life. Notch low cycle fatigue is a key mechanical property of the highly stressed gas turbine rotating components since it simulates behavior at notches and bolt holes which are the regions from where the majority of failures of rotating components tend to originate.

With the increase in the disk operating temperatures, sustained dwells (or hold times) have been shown to significantly influence NLCF fatigue life (Refs. 1 and 2). In our earlier study (Ref. 1) performed on a subsolvus P/M LSHR alloy, imposition of a $90 \mathrm{sec}$ dwell at the maximum stress reduced the NLCF life by an order of magnitude compared to cyclically loaded specimens tested under identical test conditions. However a more surprising finding in that study as well as in an earlier study performed by Bache et al. (2) was that an imposition of a $90 \mathrm{sec}$ dwell at the minimum stress produced an even greater reduction in NLCF life. In our study the imposition of the $90 \mathrm{sec}$ dwell at the minimum stress produced an almost two orders of magnitude reduction in NLCF in comparison to the cyclic tests. The earlier work by Bache et al. (Ref. 2) done on a subsolvus P/M RR1000, showed that introduction of even a $10 \mathrm{sec}$ dwell at the minimum stress produced an order of magnitude shorter NLCF lives when compared to the application of the dwell at the maximum stress.

The effect of prolonged high temperature dwells on low cycle fatigue (LCF) and NLCF behavior in this class of alloys is thought to be a product of complex interactions of cyclic fatigue loading damage, time-dependent environmental degradation and embrittlement, as well as the complex viscoplastic material response in the notch root region to temperature and load history.

Due to the above described complexities, currently available life prediction models are not able to accurately predict dwell notched low cycle fatigue life. Formulation of more accurate life prediction models requires an improved 
understanding of the damage mechanisms responsible for material degradation and accumulation of fatigue damage. The key to gaining this understanding is the identification of the active damage mechanisms for a given set of test conditions. As important as the identification of the prevalent material damage mechanisms, is an accurate assessment of the notch root stress and strain redistributions in which take place during the prolonged dwells through the visco-plastic notch root deformation response.

The approach of the current study was to isolate as much as possible the major variables which affect the dwell NLCF behavior so that their individual mechanistic contributions to material durability could be studied, quantified and modeled.

Specimens from a supersolvus heat treated ME3 P/M disk superalloy were subjected to three loading histories consisting of baseline cyclic loading, or $90 \mathrm{sec}$ cyclic dwells applied at either the maximum stress or at the minimum stress. The cyclic NLCF testing was performed to obtain a baseline data set, while the two $90 \mathrm{sec}$ dwell waveforms attempted to capture the environmental degradation which occurs as a function of high temperature exposures. Vacuum testing was performed to quantify the environmentally driven NLCF debit. The use of dwells at either the maximum stress or minimum stress was introduced so that the influence of notch root visco-plastic behavior could be evaluated. To further the evaluation of the notch root visco-plastic behavior, two different ME3 heat treatments were evaluated which are known to produce significantly different visco-plastic response.

\section{Materials and Procedure}

All specimens were blanked and machined from a powder metallurgy ME3 alloy pancake forging of the following composition in weight percent: $3.38 \mathrm{Al}, 0.025 \mathrm{~B}, 0.053 \mathrm{C}$, 20.7 Co, 12.8 Cr, 3.79 Mo, 0.90 Nb, 2.33 Ta, 3.67 Ti, 2.03 W, $0.049 \mathrm{Zr}$ and Bal. Ni. Each blank was individually heat treated to assure that the desired processing was achieved. Each blank was given the same supersolvus solutioning heat treatment at $1171^{\circ} \mathrm{C}$. The blanks were then cooled from the solutioning temperature at either 72 or $202^{\circ} \mathrm{C} / \mathrm{min}$ cooling rate as measured by an embedded thermocouple. Subsequently the blanks were given a two step age treatment consisting of $843^{\circ} \mathrm{C}$ for $4 \mathrm{hr}$ and $760^{\circ} \mathrm{C}$ for $8 \mathrm{hr}$. The blanks were subsequently machined into a circumferential notch low cycle fatigue specimens with an elastic stress concentration factor $K_{t}=2.0$. The notch was low-stress ground, then polished parallel to the loading direction to meet or exceed a $0.21 \mu \mathrm{m}$ (8 $\mu$ in.) rms finish requirement.

All testing was performed at NASA GRC using closed loop servo-hydraulic test machines equipped with resistance heating furnaces. Most of the testing was performed in a lab air environment however a selected number of specimens were tested in a test machine equipped with a vacuum chamber. The vacuum level measured in the chamber ranged mostly from $10^{-4} \mathrm{~Pa}$ to $10^{-5} \mathrm{~Pa}$. All testing was done at $704^{\circ} \mathrm{C}$.
Three waveforms were utilized, all with a minimum/ maximum applied stress ratio of $R_{\sigma}=0.05$. The baseline cyclic testing was performed with no dwells at $0.333 \mathrm{~Hz}$ frequency. For the cyclic dwell tests, $90 \mathrm{sec}$ holds were applied at either the maximum applied stress (max dwell waveform) or at the minimum applied stress (min dwell waveform). The testing for all three waveforms was performed with the maximum applied net section stress equal to either 855 or $896 \mathrm{MPa}$.

Stress relaxation testing was conducted for both cooling rate heat treatments using a $4.06 \mathrm{~mm}$ diameter cylindrical specimens machined from the heat treated blanks. The specimens were heated to $704^{\circ} \mathrm{C}$ and strained to 1 percent total strain. Subsequent stress relaxation was measured as a function of time for the $100 \mathrm{hr}$ duration of the tests.

\section{Results and Discussion}

\section{Non-Unified Visco-Plastic FEM Analysis of Notch Root Stresses}

The evolution of the notch root stresses was modeled using finite element modeling (FEM) as a function of the number of applied cycles for both max dwell and min dwell loading profiles. The notched specimen geometry was modeled with a two-dimensional axi-symmetric non-linear elements and the material modeled using a non-unified viscoplastic analysis wherein the strain is decomposed into separate elastic, plastic, creep, and thermal components. The analysis utilized material properties such as elastic modulus, flaw strength, and relaxation behavior which were determined through tensile tests performed at $704{ }^{\circ} \mathrm{C}$ for both ME3 heat treatments using a constant strain rate $\left(8.5 \times 10^{-5} 1 / \mathrm{s}\right)$. Upon reaching 1 percent total strain, the tensile specimens were used to conduct $100 \mathrm{hr}$ stress relaxation tests. The purpose of the present analysis was to capture the trend of stress state evolutions at the notch root and to help understand the effect of stress relaxation behavior, and consequently stress redistribution, on fatigue life during two different dwell loading profiles. Stress state at the notch root was monitored for the first 100 applied dwell cycles. While the analysis was performed to capture the above mentioned trends, more rigorous analysis will be performed in the future to capture the effect of the loading rate and creep/plasticity interactions.

The plastic strain was computed using the Von Mises plasticity model within Abaqus, the required material parameters being obtained from the tensile curves are shown in Figure 1(a). The stress relaxation material response was correlated using the following creep law:

$$
\dot{\varepsilon}=A \sigma^{n} t^{m}
$$

where $\dot{\varepsilon}$ is the strain rate, $\sigma$ is stress, $t$ is time and $A, n$ and $m$ are fitting constants. The creep coefficients which fit this 
equation for both heat treatments were determined and are shown in Figure 1(b). The figure shows the measured and analytically modeled axial stress relaxation response as a function of time for the two cooling rates after an application of a 1 percent total strain. As shown, the high strength (more creep resistant), fast cooled heat treatment resulted in consistently 50 to $100 \mathrm{MPa}$ higher stresses throughout the test in comparison to the lower strength, slow cooled heat treatment. The non-unified visco-plastic creep analysis of the stress relaxation response resulted in an excellent correlation with the experimentally measured stress relaxation for both heat treatments.

The above non-unified visco-plastic creep analysis was used to perform FEM modeling of the circumferential notch root stresses. The estimated maximum axial stresses generated at the notch root for both ME3 cooling rates as a function of the maximum and minimum dwell cycles are compared in Figure 2. As shown, the initial magnitude of the notch root stresses is similar for both dwell loading waveforms, however in the case of the max dwell waveform the notch root stresses decrease rapidly during subsequent cycles. In comparison, for the minimum dwell tests the maximum notch root cyclic stress remained almost constant throughout the duration of the test. Thus, as the number of dwell cycles accumulates, the differences in the notch root stresses between min and max dwell load profiles increase and therefore may have a substantial effect on the dwell NLCF behavior. Again, the magnitude of stress may not be accurate since some of the non-linear material responses were not precisely modeled. Yet, the trend of stress evolution during the max and the min dwell loading profile under the same $0.33 \mathrm{~Hz}$ loading rate should be qualitatively the same.

The effect of the difference in the cooling rates on the notch root stresses is also significant. While the trends are very similar for both cooling rates, the actual magnitude of the notch root stresses is consistently 50 to $75 \mathrm{MPa}$ higher for the fast cool heat treatment for both the min and the max dwell loading profiles (Fig. 2).

\section{NLCF Testing}

The results of the NLCF tests conducted in the laboratory air environment at a maximum stress of $855 \mathrm{MPa}$ for the three load histories investigated are shown in Figure 3. The specimens tested without dwells at a $0.333 \mathrm{~Hz}$ frequency produced the longest lives, while the applied max and min dwell tests resulted in a pronounced fatigue debit for both waveforms. The cyclic lives were in the order of 80,000 to 110,000 cycles, while the max dwell tests duration was approximately 20,000 cycles with the min dwell tests lives being in the 10,000 cycle range. As shown in the figure, the cooling rate did not significantly alter either the $0.333 \mathrm{~Hz}$ or the min dwell tests (specimens with only the fast cool condition were tested under the applied $855 \mathrm{MPa}$ max dwell

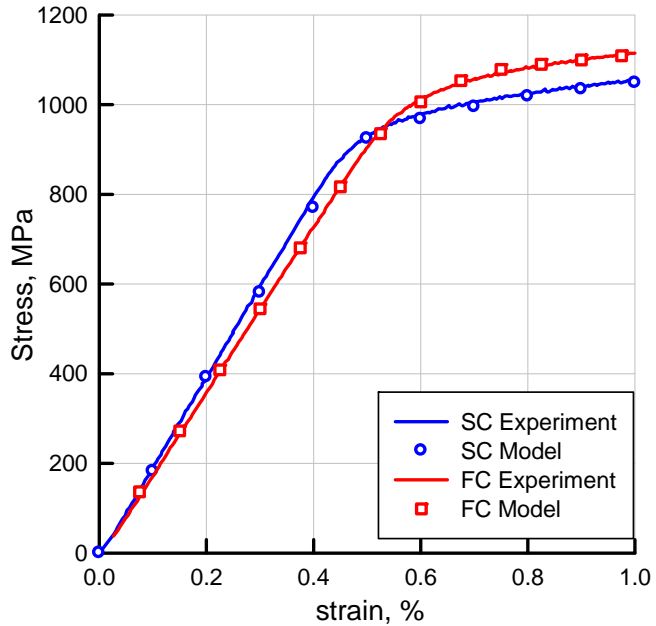

(a)

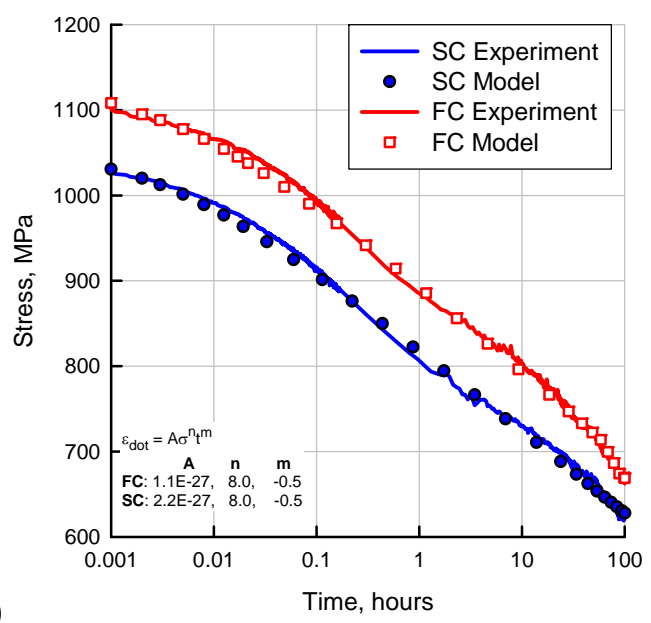

(b)

Figure 1.-Simulation of the experimentally measured tensile and stress relaxation tests. (a) Tensile testing and modeling. (b) Stress relaxation testing and modeling.

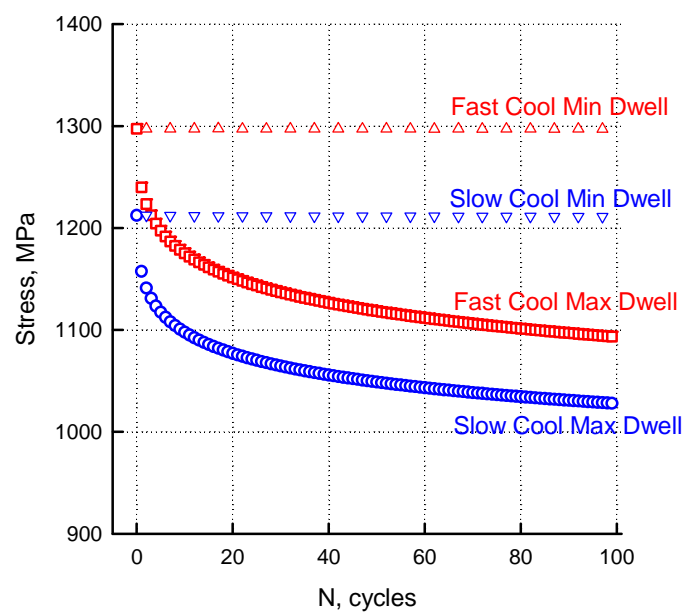

Figure 2.-FEM modeling of the notch root axial stresses as a function of applied dwell waveform and number of cycles for both slow and fast cooled heat treatments. 


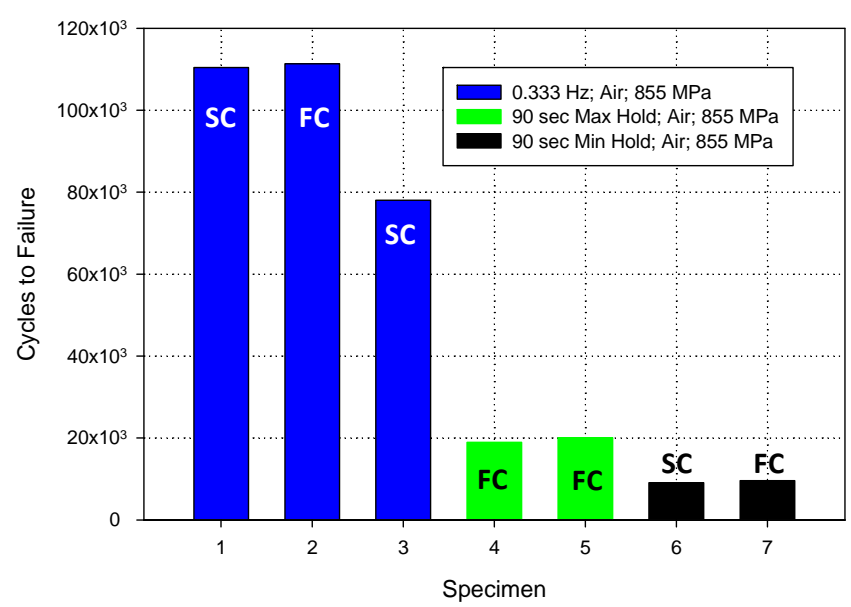

Figure 3.-NLCF lives for the three different waveforms at an applied $855 \mathrm{MPa}$ max stress.

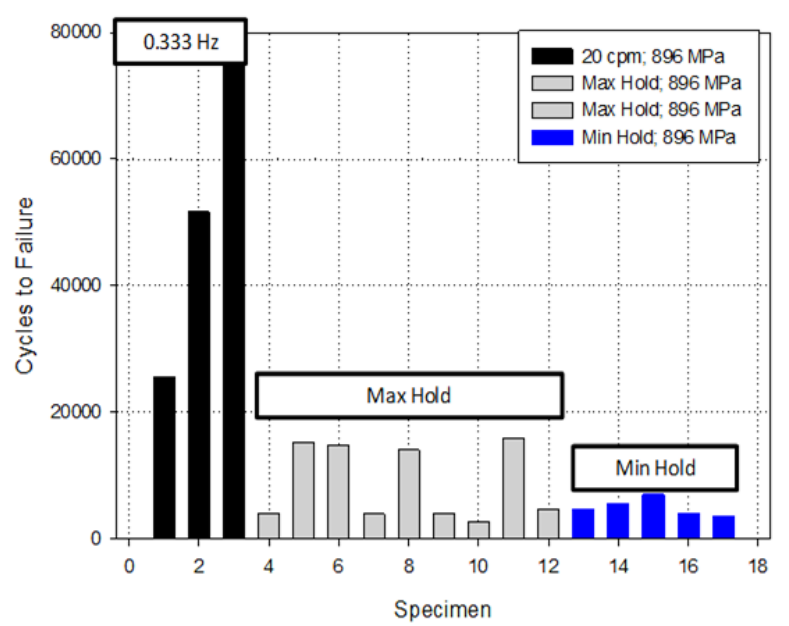

Figure 4.-NLCF lives for the three different waveforms at an applied $89 \mathrm{MPa}$ max stress.

waveform). These observed trends were similar to those reported earlier for both the subsolvus LSHR and RR1000 $\mathrm{P} / \mathrm{M}$ alloys with the min hold waveform exhibiting the shortest lives (Refs. 1 and 2).

The results of the NLCF tests conducted in air at a maximum stress of $896 \mathrm{MPa}$ were more difficult to interpret with regards to the data trends. As shown in Figure 4, the NLCF fatigue lives of the cyclic tests conducted at $0.333 \mathrm{~Hz}$ still resulted in the longest lives (ranging from 25,000 to 75,000 cycles) in comparison to the dwell tests, even though the life scatter was greater than for the $855 \mathrm{MPa}$ max stress cyclic tests. The $90 \mathrm{sec}$ min dwell tests exhibited fairly uniform short fatigue lives in the range of 3,500 to 7,000 cycles. However, the $90 \mathrm{sec}$ max dwell test results were more complex. The NLCF fatigue lives of the max dwell tests exhibit a bimodal distribution with one group showing failure lives of approximately 4,000 cycles while the other group of specimens failed at approximately 15,000 cycles.

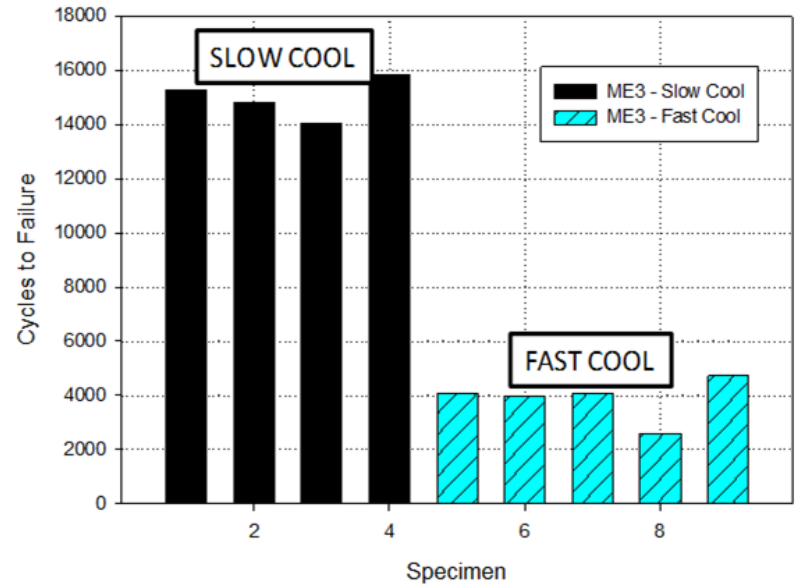

Figure 5.-The NLCF results for the max dwell tests performed at $896 \mathrm{MPa}$, show that the cooling is an important variable.

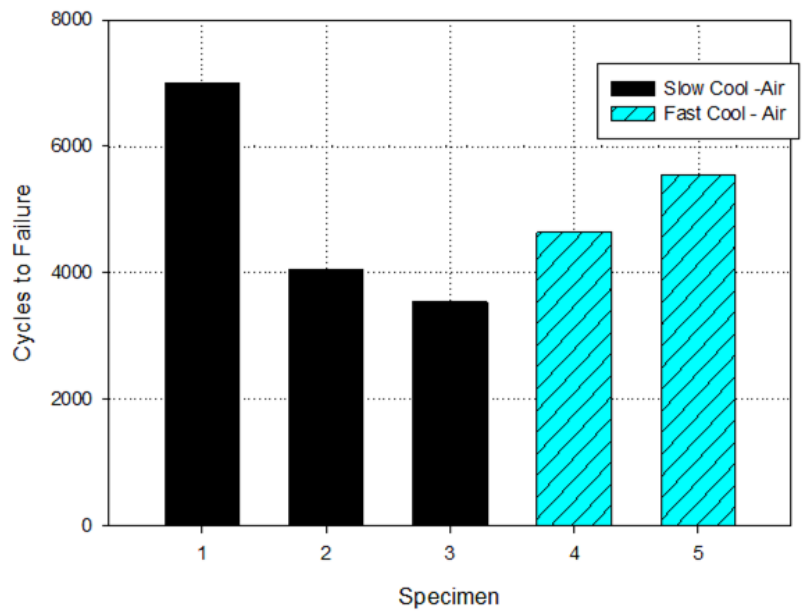

Figure 6.-For the min dwell tests at $896 \mathrm{MPa}$, the NLCF results are not a function of the cooling rate.

The NLCF dwell data for the $896 \mathrm{MPa}$ max dwell tests is replotted in Figure 5, this time with the cooling rate from the solutioning temperature assigned for each specimen. The replotted results show very clear trends. All the slow cooled max dwell specimens resulted in NLCF lives of approximately 15,000 cycles while all the fast cool specimens failed at approximately 4,000 cycles.

In case of the $896 \mathrm{MPa}$ min dwell tests (Fig. 6), the fatigue lives were very similar regardless of the cooling rate. These results suggest that not only the dwell waveform but also the cooling rate has a pronounced effect on NLCF behavior. Furthermore, in the case of the max dwell waveform, the fast cooled specimens fatigue lives were also very sensitive to the applied net section stress. The increase in the applied dwell stress from 855 to $896 \mathrm{MPa}$ resulted in an almost $5 \times$ reduction in cycles to failure. In comparison the same increase in the max stress for the min dwell tests resulted in only a $2 \times$ reduction in NLCF lives. 


\section{Vacuum Testing}

Numerous vacuum tests were conducted to ascertain the role of environment on the NLCF behavior of this alloy. The fatigue results for all three load histories tested in vacuum at a max stress of $896 \mathrm{MPa}$ are shown in Figure 7. The fatigue lives of the cyclic specimens were on the order of 70,000 cycles and remained considerably longer than those of the min and max dwell specimens. There was no longer a substantial difference between the fatigue lives of min and max dwell specimens with the failures occurring at approximately 18,000 to 20,000 cycles regardless of the dwell waveform or the cooling rate. The most dramatic difference between air and vacuum is exhibited by the min dwell tests as shown in Figure 8. The NLCF life was increased approximately by a factor of four by changing the test environment from air to vacuum with no clear influence of the cooling rate.

For max dwell tests of the slow cooled heat treatment, the change in the environment from air to vacuum had a less dramatic impact on the NLCF lives, with the vacuum max dwell specimens exhibiting approximately a 25 percent increase in life (Fig. 9). However, as shown in the same figure, for the fast cooled specimens the fatigue lives of the max dwell tests were four to five times longer in vacuum than in air.

\section{Fatigue Damage Mechanisms}

The NLCF testing produced a number of interesting results, which required further analysis to explain the observed trends. Extensive fractographic analysis of the microstructural damage mechanisms was performed using scanning electron microscopy (SEM). The focus was to identify and compare the failure mechanisms of min and max dwell NLCF tests in both air and vacuum environments so that the differences in the NLCF fatigue lives could be explained. Additionally, the role of the cooling rates from the solutioning treatment on the prevailing damage mechanisms was also examined.

The fractography performed on the failed NLCF specimens revealed a variety of operative fatigue initiation and propagation modes that depended on the applied loading waveform, test environment and the cooling rate.

\section{Max Dwell Testing-Air}

Fast cooled NLCF specimens tested under max dwell loading, exhibited a predominant intergranular crack initiation and propagation failure mode for all specimens tested under this waveform as shown in Figure 10(a) and (b). This was the case for the specimens tested at the $896 \mathrm{MPa}$ max stress (Fig. 10(a)) which resulted in relatively short lives as well as the specimens tested at $855 \mathrm{MPa}$ (Fig. 10(b)) which resulted in much longer NLCF lives. The extensive intergranular notch root surface damage which occurred during the test is clearly visible in the surface region adjacent to the primary crack (Fig. 10(b)).

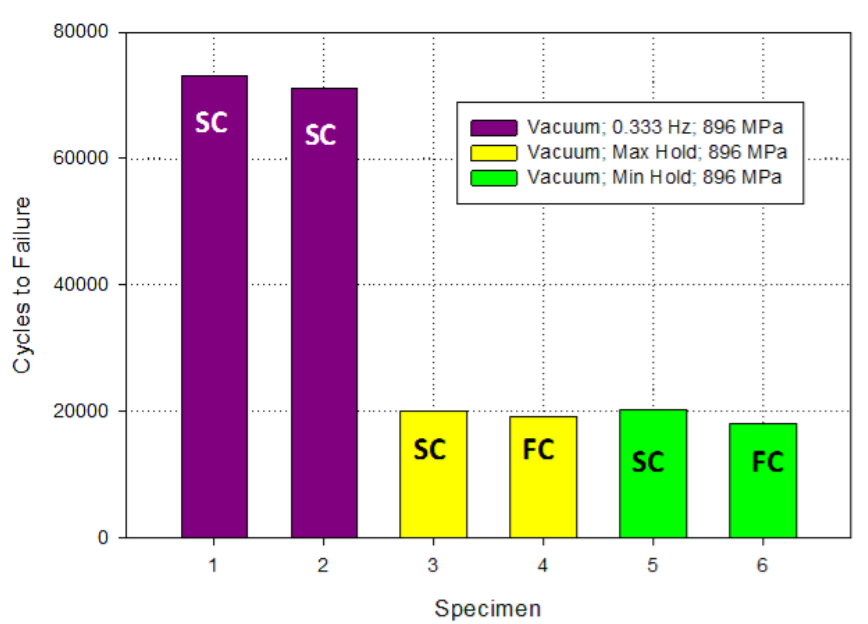

Figure 7.- Vacuum NLCF results for the three waveforms tested at $896 \mathrm{MPa}$.

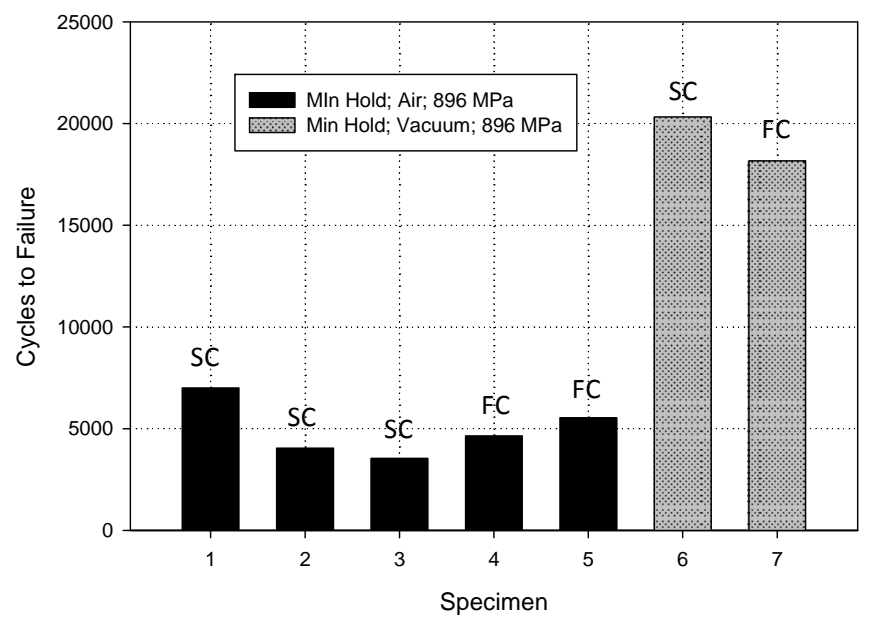

Figure 8.-Comparison of air and vacuum NLCF results for the min dwell waveform for tests conducted at $896 \mathrm{MPa}$.

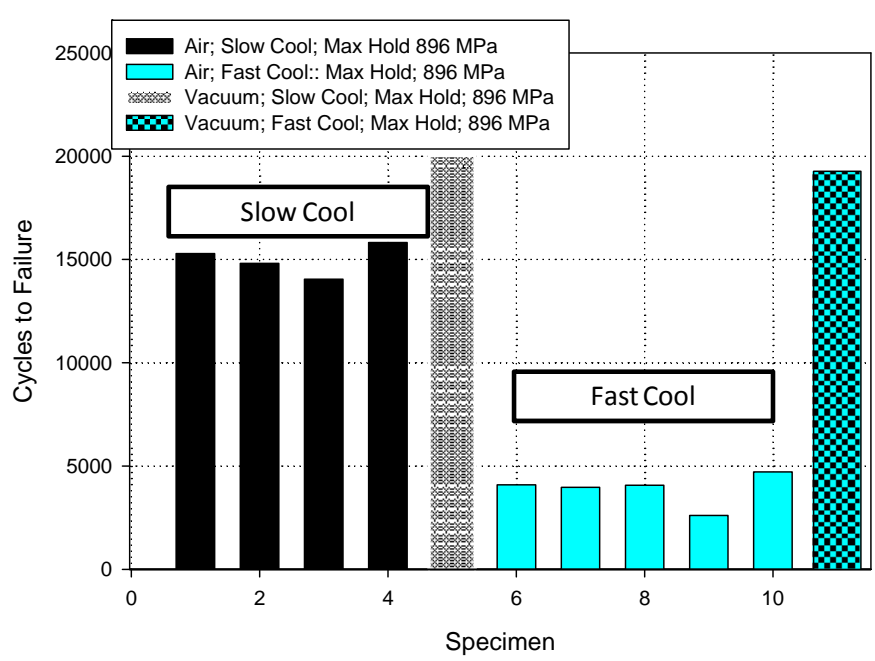

Figure 9.-Max dwell NLCF lives in vacuum and air for the two heat treatments tested at $896 \mathrm{MPa}$. 

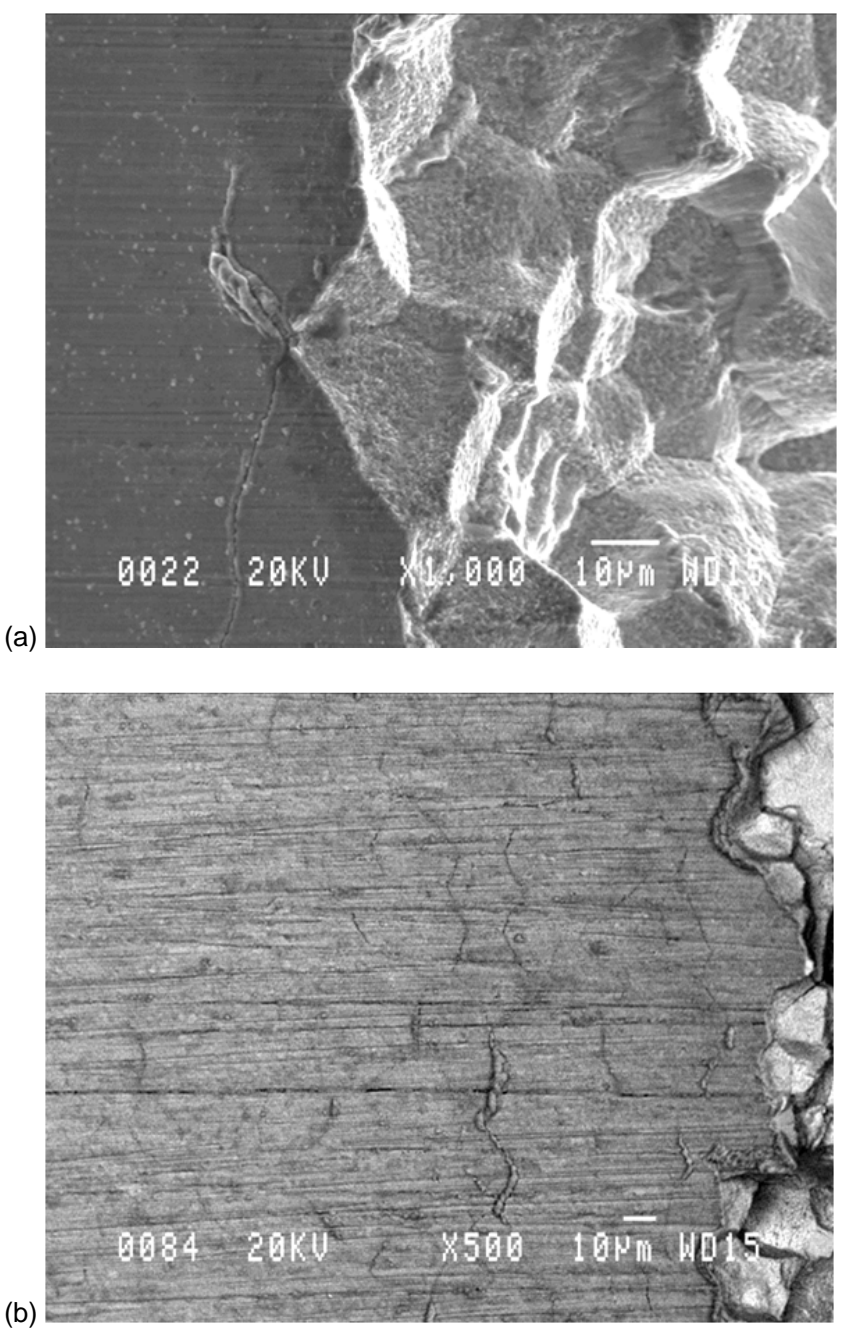

Figure 10.--Intergranular initiation, propagation and secondary cracking for fast cooled specimens tested using the max dwell waveform, loading axis horizontal. (a) Max dwell test performed with an $896 \mathrm{MPa}$ hold stress on a fast cooled NLCF specimen; Nf = 3,969 cycles. (b) Max dwell test performed with an $855 \mathrm{MPa}$ hold stress on a fast cooled NLCF specimen; Nf = 18,942 cycles. Back scatter image.

The initiation and propagation failure modes in the slow cooled max dwell specimens differ somewhat in comparison to the fast cooled specimens. As shown in Figure 11, both transgranular and intergranular crack initiation regions were present in the slow cooled specimens (Fig. 11(a)). The transgranular region typically extended up to approximately $100 \mu \mathrm{m}$ into the specimen, after which intergranular propagation dominated (Fig. 11(b)). This behavior was consistent for all specimens examined.

The presence of intergranular initiation and propagation failure mechanisms in max dwell tests was expected. It has been shown repeatedly (Refs. 3 to 5) that the presence of a prolonged tensile holds in air promotes intergranular failure mechanisms which are known to accelerate grain boundary (a)

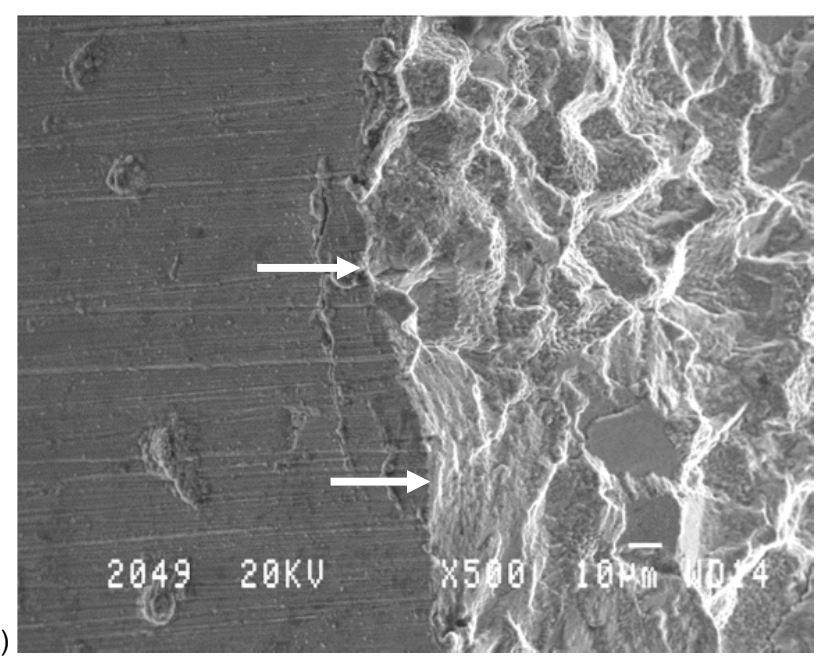

(b)

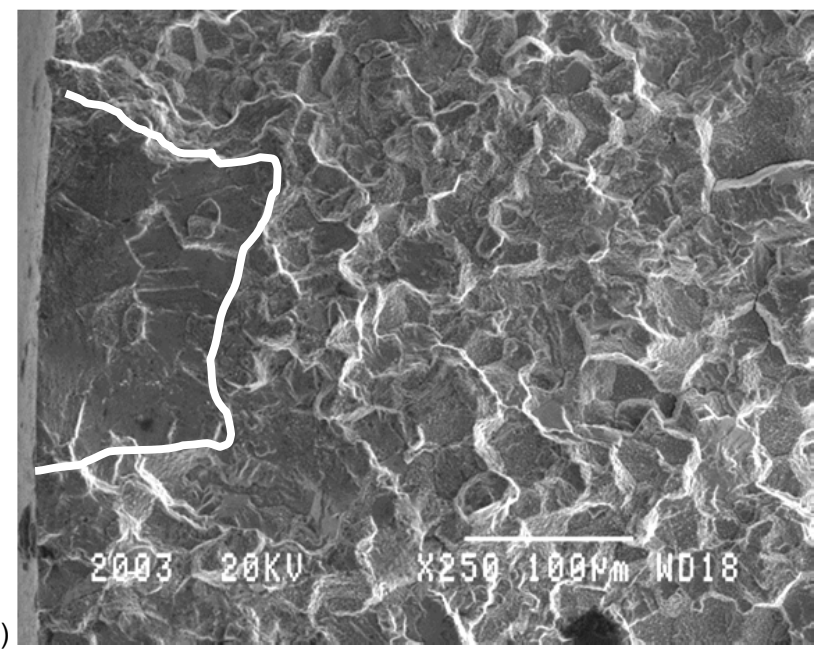

Figure 11.-Mixed mode initiation and propagation in slow cooled max dwell NLCF specimens tested at $896 \mathrm{MPa}$ max stress. (a) Intergranular initiation (upper arrow) and transgranular initiation (lower arrow), horizontal loading axis. (b) Region of transgranular initiation surrounded by intergranular propagation.

damage. The observed differences in the amount of intergranular initiation and propagation between the two cooling rates may be due to a combination of higher notch root stresses in the case of fast cooled material (Fig. 2) and the possibility that the higher cooling rate may produce a grain boundary structure which is more susceptible to intergranular failure.

Combination of the above described mechanisms may explain the observed differences in the max dwell NLCF lives between the fast and slow cooled heat treatments tested at $896 \mathrm{MPa}$. A greater propensity for grain boundary environmental attack tied in with higher notch root stresses for the fast cooled material could have led to early intergranular crack initiation and failure for this heat treatment in 
comparison to slow cooled specimens which were subjected to lower notch root stresses and may possess microstructure less sensitive to grain boundary attack.

\section{Min Dwell Testing-Air}

The min dwell NLCF fatigue lives for both fast cooled and slow cooled specimens tested in air were very short and did not appear to be correlated with the cooling rate (Figs. 3 and 6). The failure mode of the slow and fast cooled min dwell NLCF specimens are shown in Figures 12 and 13, respectively. For the slow cooled specimens, predominantly transgranular initiation and propagation failure modes were observed (Fig. 12).

The fractography of the fast cooled specimens tested using the min dwell waveform showed that crack initiation occurred through a mixture of both transgranular and intergranular crack failure modes (Fig. 13). Interestingly, even after a transgranular initiation, a 50 - to $75-\mu$ m-deep region of intergranular crack propagation was present which transitioned again to a transgranular failure mode for the rest of the test (Fig. 13(b)). Thus, while there were some differences in the failure mode between the two cooling rates for the min dwell tests, the transgranular failure mode was active for both cooling rates.

\section{Interrupted Testing}

Transgranular initiation and propagation are usually considered more benign failure mechanisms than intergranular attack. However in the case of the min dwell cycle tests which mostly exhibited transgranular failure mechanisms, their NLCF lives were either equivalent or in many cases much lower than the comparable max dwell tests which tended to exhibit an intergranular failure mode. It is clear from these

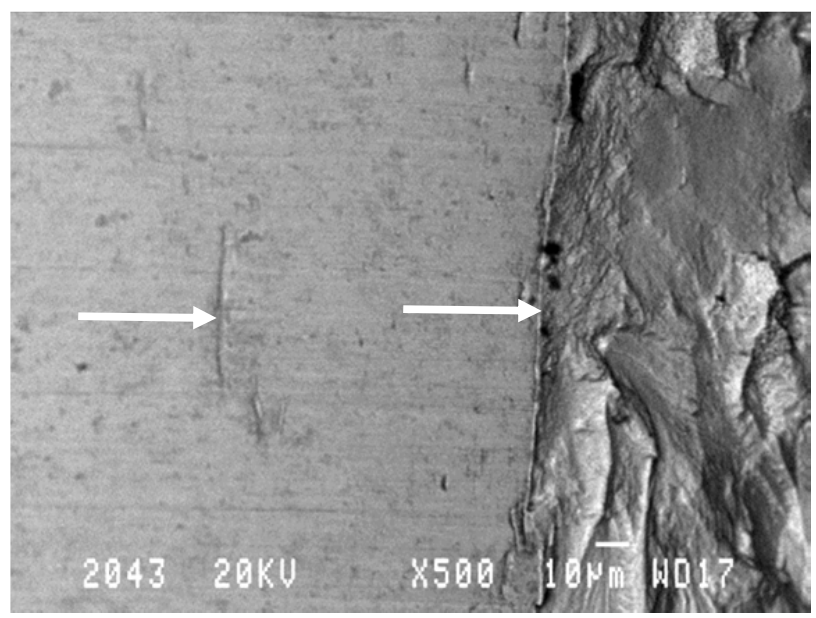

Figure 12.-Predominant transgranular initiation and propagation for slow cooled specimens tested using min dwell waveform, horizontal loading axis.
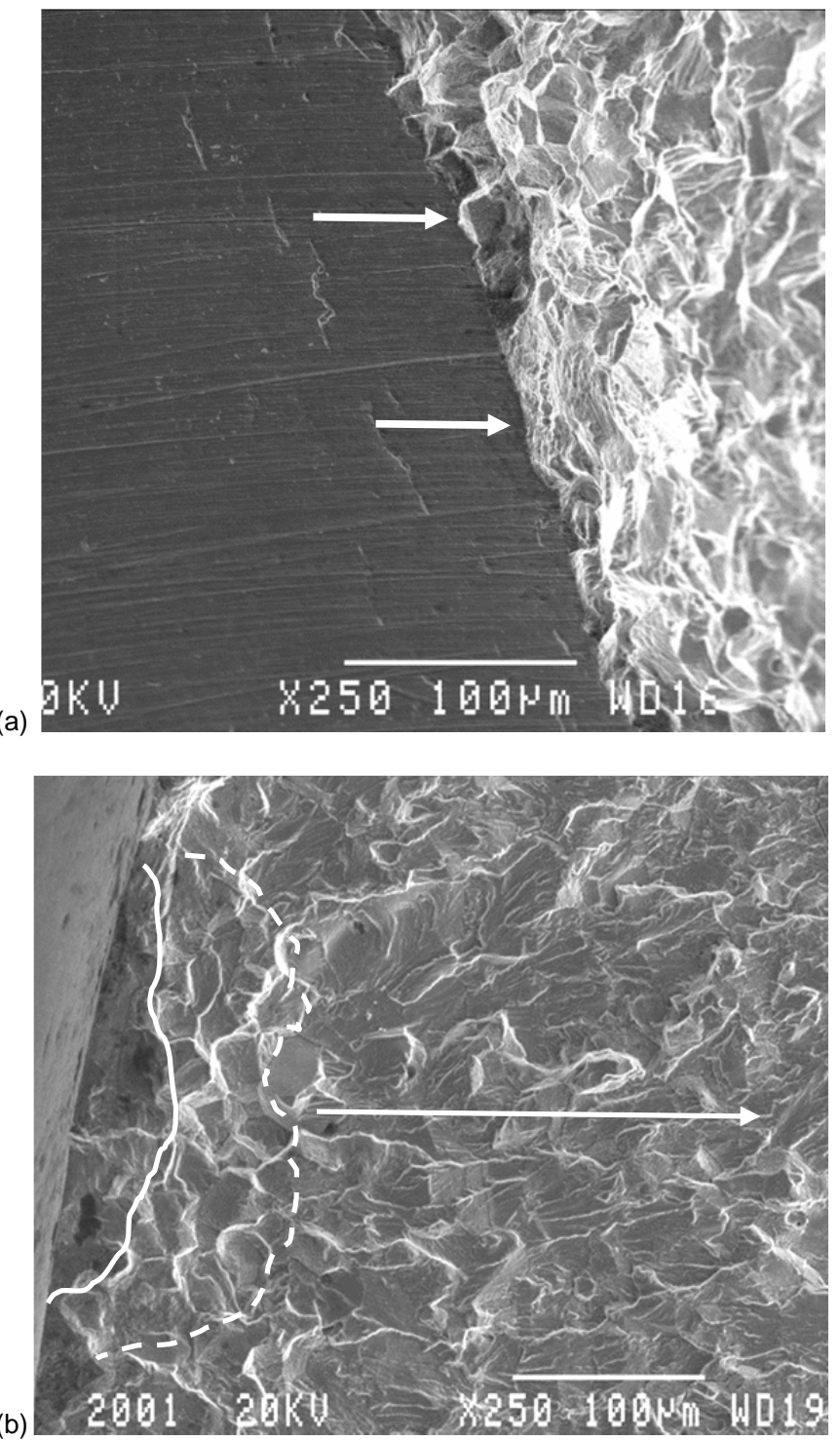

Figure 13.-Mixed mode initiation and propagation in fast cooled specimens tested using min dwell waveform. (a) Intergranular initiation (upper arrow) and transgranular initiation (lower arrow), horizontal loading axis. (b) Transgranular initiation, small region of intergranular propagation (dashed lines) followed by additional transgranular propagation (arrow).

results that simplistic assumptions regarding transgranular versus intergranular failure mechanisms cannot be used to explain the current NLCF results. More in-depth knowledge of the failure mode mechanisms and the variables which control crack initiation and propagation is required.

In order to gain a better understanding of the operative crack initiation mechanisms and how they can influence NLCF behavior, interrupted tests were conducted in air and vacuum for NLCF specimens subjected to the min dwell loading waveform. Only specimens given the slow cooled heat treatment were used. All tests were interrupted after 
1000 cycles, the specimens removed from the test rig and placed in the SEM for examination.

As observed in the SEM for the two air tested specimens, numerous cracks were already visible in the notch root section after the application of 1000 cycles which corresponds to approximately 20 to 25 percent of the expected lives (Fig. 14). The detailed SEM and EDS evaluation of these interrupted tests revealed two different crack initiation mechanisms which were responsible for the early crack initiation in the lab air environment.

One of these crack initiating mechanisms is discernible in Figure 14. It is apparent in the back scatter image shown in Fig. 14(a), that all the visible cracks are associated with the irregularly distributed darker regions present on the notch surface. No cracks appeared to have initiated in the lighter regions of the image. Secondary electron images and the EDS analysis of these crack initiating regions showed that they consisted of oxide-like scales (Fig. 14(b) and (c)) which grew preferentially during the first 1000 cycles of min dwell testing. These oxide scales were found to be considerably higher in $\mathrm{Cr}$, $\mathrm{Ti}$ and oxygen content in comparison to the adjacent uncracked regions (light regions of Fig. 14(a)). Preliminary results from a recently performed $\mathrm{x}$-ray diffraction analysis positively identified these phases as chromium oxide, $\mathrm{Cr}_{2} \mathrm{O}_{3}$, and titanium oxide, $\mathrm{TiO}_{2}$.

It is proposed that the early formation and growth of these irregularly distributed oxide colonies results in the creation of brittle phases which can crack when the scales reach some critical thickness and are subjected to sufficiently high applied stresses. The cracks emanating from these oxides propagate into the surrounding metal and eventually lead to premature failure. Since these oxide scales are not associated with grain boundaries, transgranular cracks can form as was observed in the tested specimens. As shown in the visco-plastic FEM analysis (Fig. 2), very little notch root stress relaxation occurs as the min dwell cycles are accumulated, thus the maximum cyclic stress remains high for the duration of the test while the oxide scales form and grow during the min holds. This combination of high max cyclic stresses and prolonged exposures in an environment conducive to the growth of brittle phases may account for the reduced NLCF life of the min dwell tested NLCF specimens.

A second crack initiation mechanism was also detected in the min dwell NLCF tests performed in lab air. The notch root surface contained a large number of very small particles which appeared to have already been broken up after 1000 cycles (Fig. 15). These particles, which are approximately 0.3 to $1 \mu \mathrm{m}$ in diameter, were not easily detected prior to start of the tests, but were clearly visible on the surface after the application of 1000 dwell cycles. While the identification of these particles has not been finalized, they are most likely MC carbides which have reacted with oxygen, became brittle, and fractured during testing. EDS analysis showed them to be rich in Ta, Ti, Mo and O. A small percentage of these fractured particles have initiated cracks

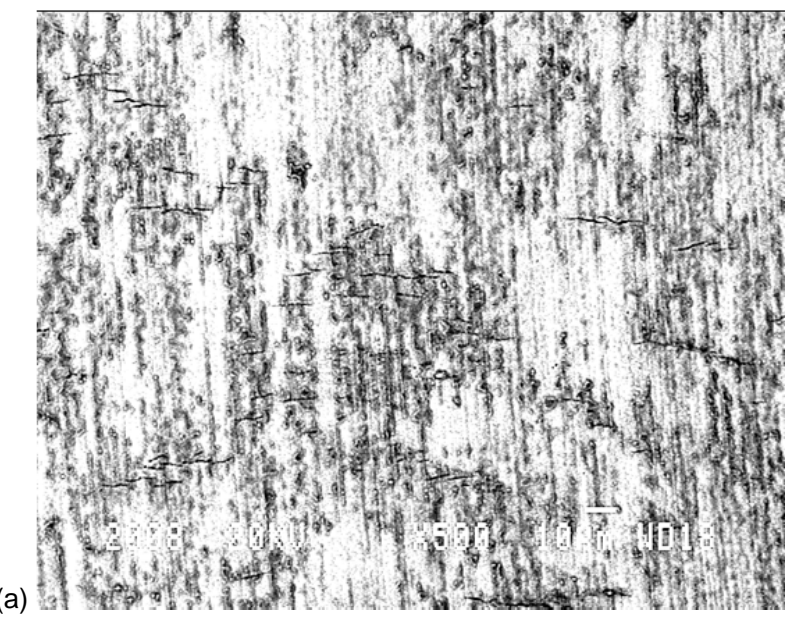

(b)

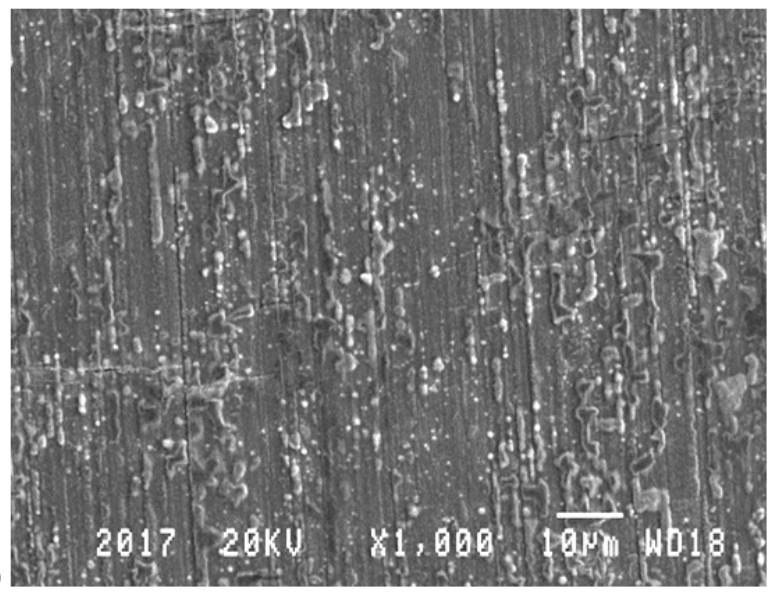

(c)

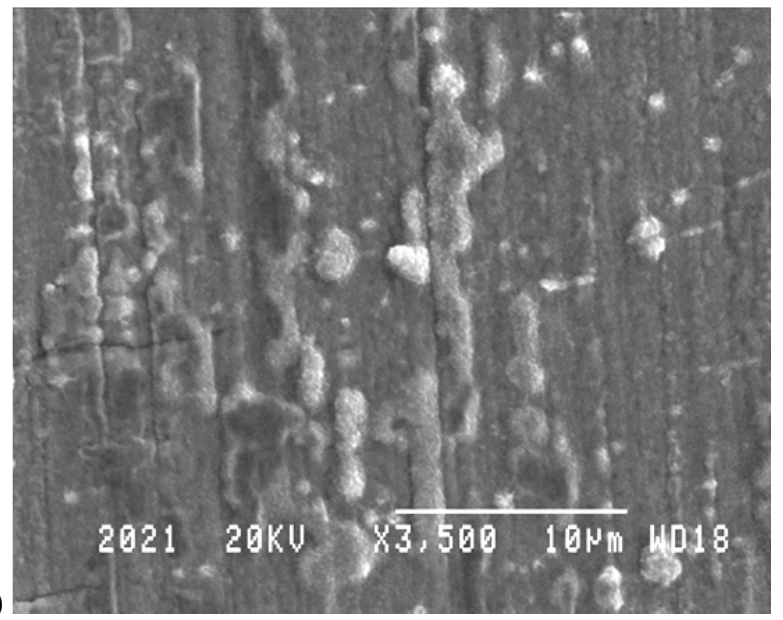

Figure 14.-Observations of transgranular initiating from the preferentially oxidized notch surface regions. Vertical loading axis. (a) Back scatter image of a min hold specimen tested in air. Extensive cracking confined only to the darker phases present on the notch surface. (b) Secondary image showing the cracked regions corresponding to irregularly spaced oxide scale on the surface. (c) Higher mag image of cracking from the oxide scale. 


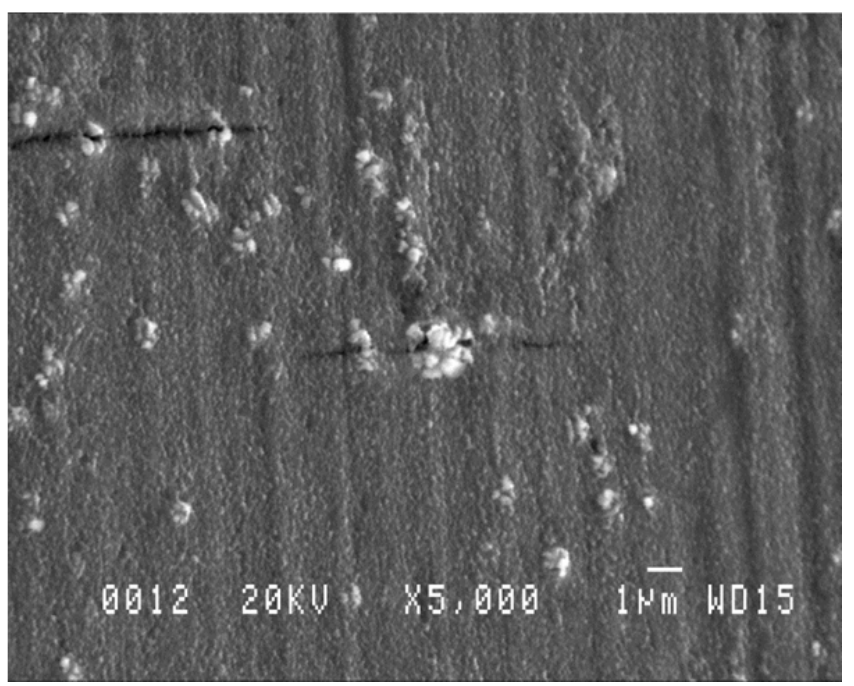

Figure 15.-Multiple broken up small particles (probably MC carbides). Few of these particles initiated cracks. Vertical loading axis.

which started to propagate into the surrounding metal during the initial 1,000 cycles (Fig. 15).

As was the case for the oxide scale cracking, the propagation of the cracked and oxidized carbides into the surrounding metal may require the higher max cyclic stresses present for the min dwell loading profile. Thus both of these mechanisms can contribute to early failure of the NLCF min dwell specimens. It should be noted that the frequency of the cracks starting from the oxidized MC carbide particles was considerably lower than those which initiated from the previously described mechanism shown in Figure 14.

While the growth of the brittle oxide-scale phases and breakup of the carbides was also noted in the max dwell tests, the lower magnitude of notch root stresses due to visco-plastic stress relaxation may delay early crack initiation from these phases and thus prolong the lives of the max dwell NLCF tests as was observed in the test program. Interrupted max dwell tests are currently being performed to confirm this hypothesis.

\section{Vacuum Testing}

Max and min dwell vacuum testing produced very similar NLCF fatigue lives (Fig. 7) which typically exceeded the NLCF lives of tests performed in air (Fig. 4). The crack initiation and propagation failure modes in vacuum were strictly transgranular for both types of dwell waveforms were (Fig. 16). The difference in the failure mode between air and vacuum are especially striking when the comparison between the max dwell tests is attempted. The high oxygen content lab air resulted in predominant intergranular failure mode (Fig. 10) while the low oxygen vacuum environment resulted in a transgranular failure appearance. (a)

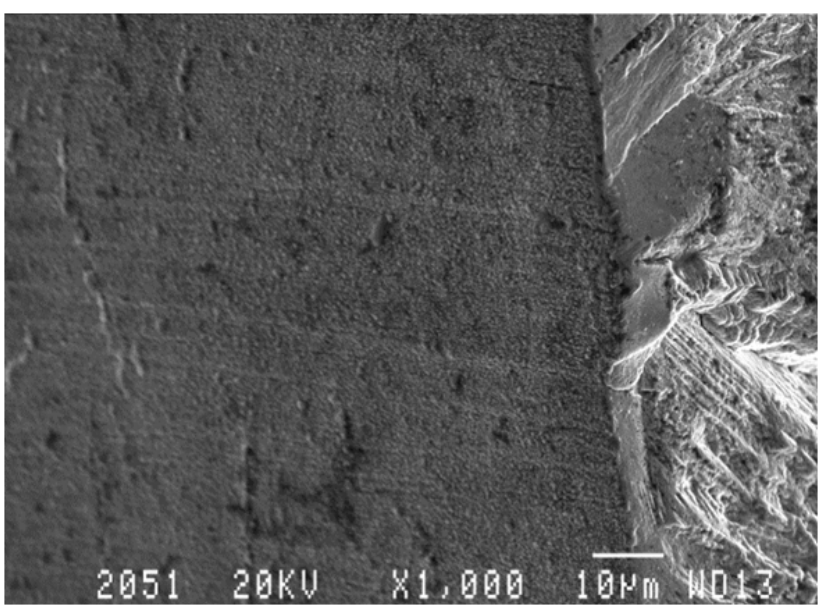

(b)
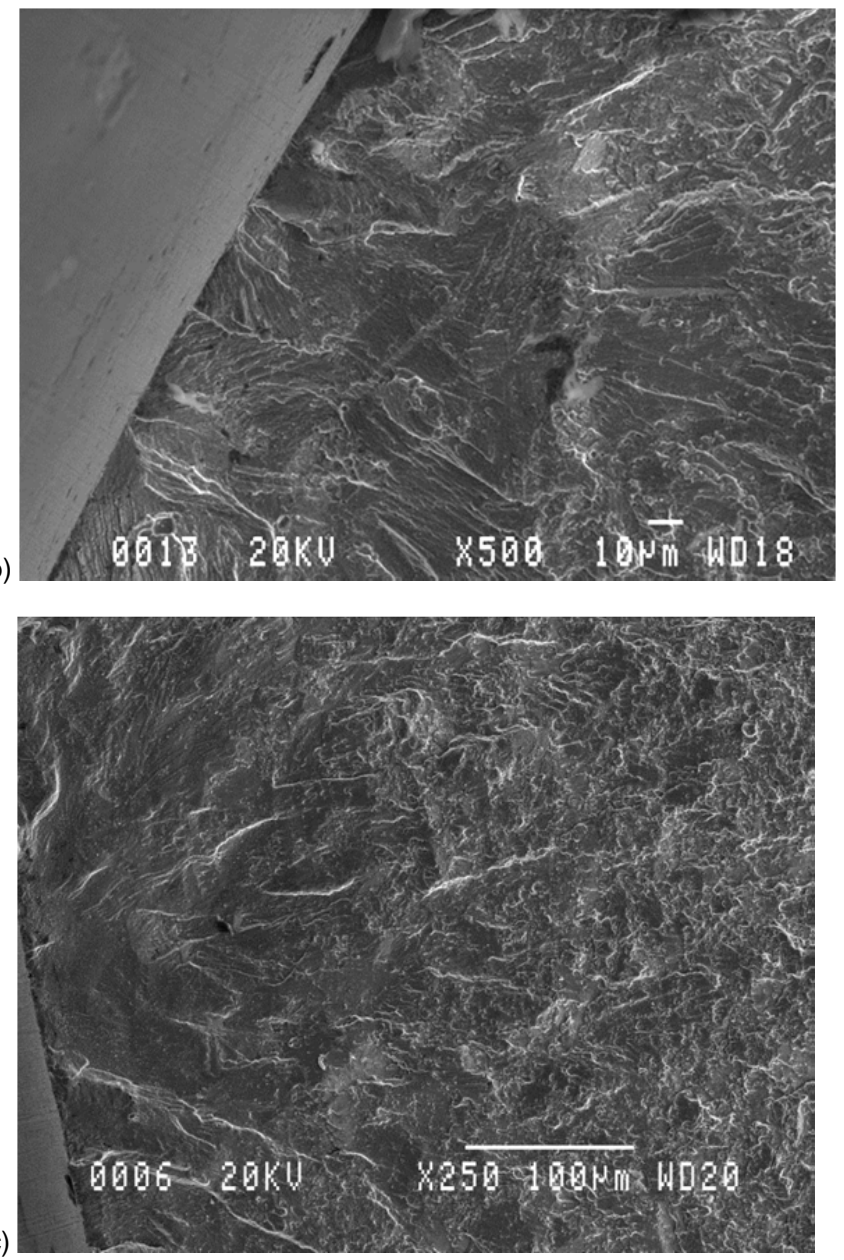

Figure 16.-Strictly transgranular initiation and propagation for both min and max dwell NLCF tests conducted in vacuum.

(a) Transgranular initiation failure mode in a max dwell test performed in vacuum. Horizontal loading axis diffraction.

(b) Transgranular propagation in a max dwell test conducted in vacuum. (c) Transgranular initiation propagation in a vacuum min dwell test. 
A more unexpected and interesting finding was the comparison of the notch surfaces of the specimens tested in air and vacuum. Figure 17 shows a comparison of air and vacuum notch regions for two tests for which the NLCF lives were comparable (18,000 to 20,000 cycles). The differences are striking, the air test shows previously described localized colonies of oxide scale and broken up carbides (Fig. 17(a)), while the vacuum tested specimen shows a dense homogenous coating of the notch surface with fine particles (Fig. 17(b)). A cross section through the vacuum tested specimen performed in a focus ion beam (FIB) microscope (Fig. 17(c)) shows these particles to be approximately 0.5 to $1.0 \mu \mathrm{m}$ thick. Initial assessment of these vacuum grown particles was done using $\mathrm{x}$-ray diffraction.

(a)

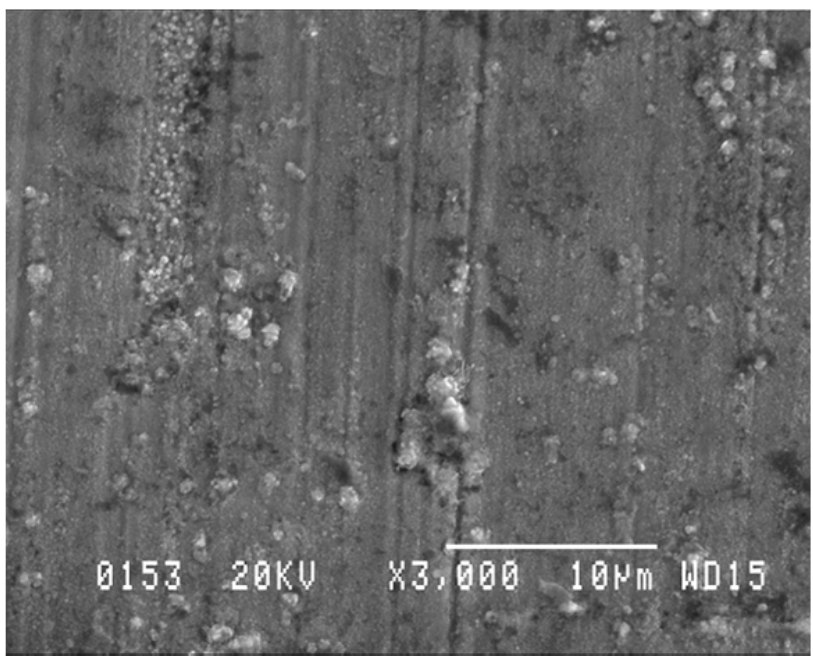

The results from this preliminary analysis indicated that two types of $\mathrm{Cr}$-Co metallic phases formed on the vacuum exposed surface. The predominant phase had a tetragonal structure with a $0.6 \mathrm{Cr}-0.4 \mathrm{Co}$ composition, while the presence of a $0.25 \mathrm{Cr}-0.75 \mathrm{Co}$ hexagonal phase was also detected. No oxide phases were observed. Further work is in progress to determine the origin of these phases.

The surface of the 1000 cycle vacuum interrupted min dwell test showed that the continuous scale of these phases was already present on the notch surfaces at this early stage of the test (Fig. 18). In contrast to the lab air interrupted tests, no cracking after 1000 cycles was detected in the vacuum interrupted min dwell test. (b)

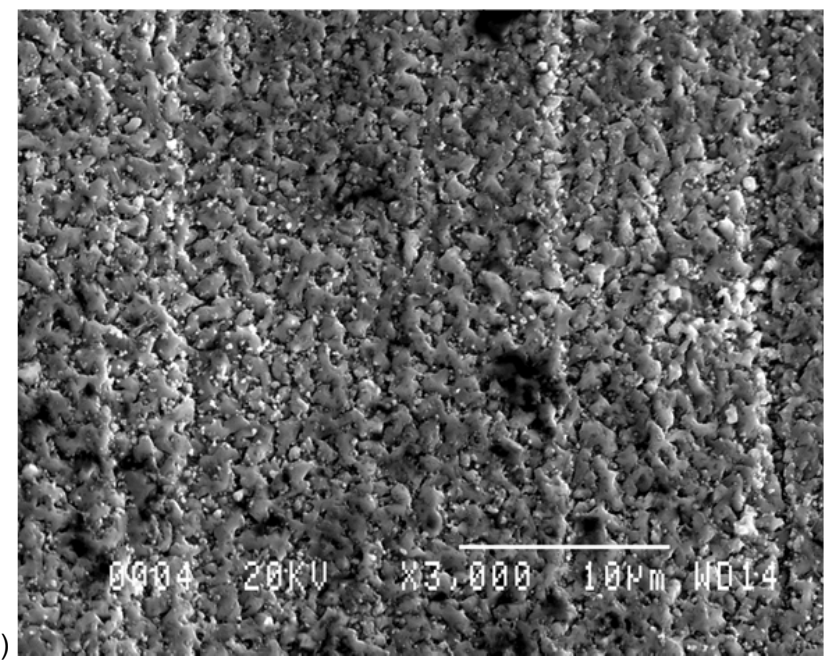

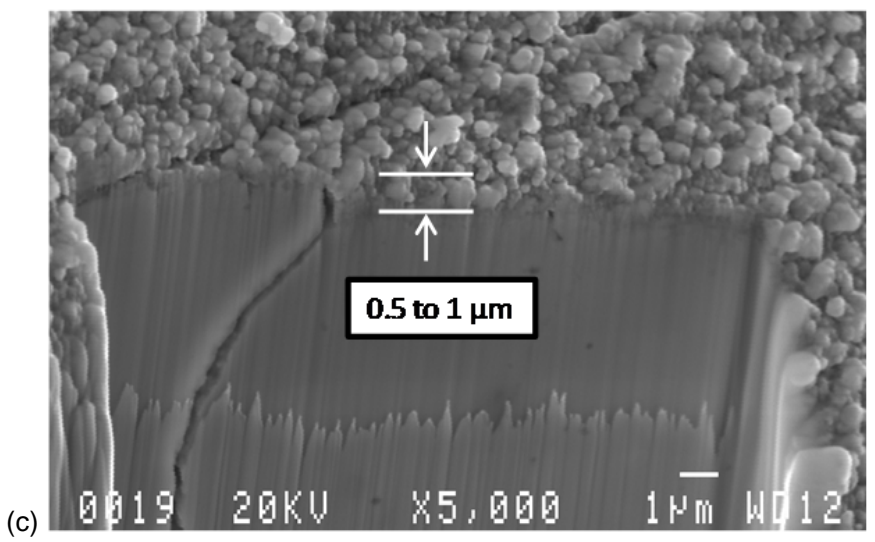

Figure 17.-Comparison of the notch root surfaces for tests performed in air and vacuum at an approximately similar testing time. (a) Notch surface of a specimen tested in air for approximately $460 \mathrm{hr}$. Max dwell at $855 \mathrm{MPa}$. Vertical loading axis.

(b) Notch surface of a specimen tested in vacuum for approximately $500 \mathrm{hr}$. Min dwell at $896 \mathrm{MPa}$. Vertical loading axis.

(c) Cross section through the notch surface of a vacuum tested specimen. Sectioning performed using a FIB microscope. 


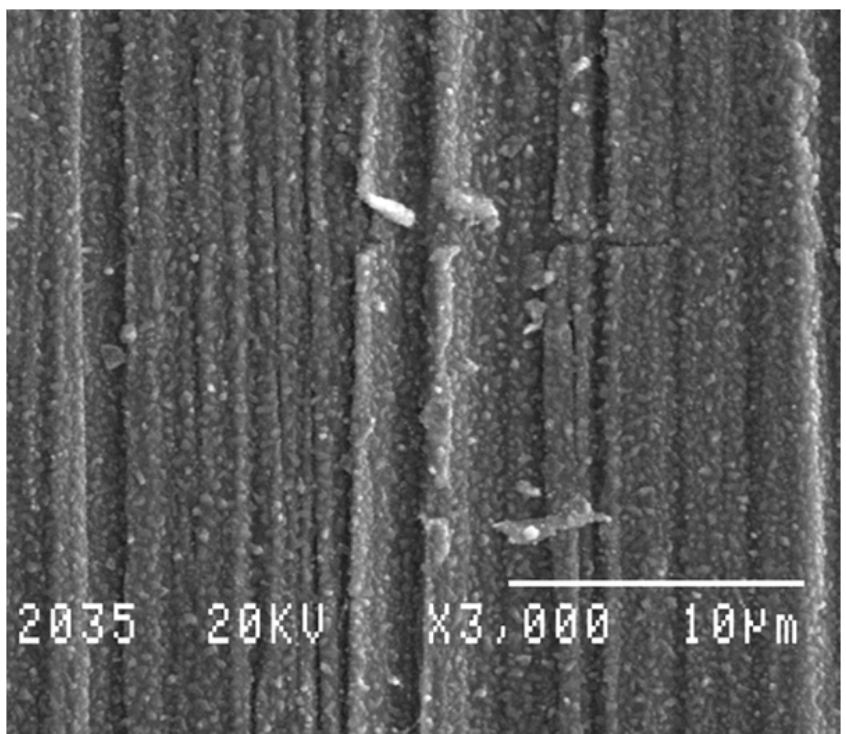

Figure 18.-Notch surface after 1000 min dwell cycles in vacuum. Continuous scale of small particulates already present. No cracking was detected (horizontal line seen in the top half of image is a left over machining groove). Vertical loading axis.

\section{Summary}

A study was conducted to determine the processes which govern dwell NLCF behavior of a P/M ME3 disk alloy. The emphasis was placed on the environmentally driven mechanisms which may embrittle the highly stressed notch surface regions. In conjunction with the environmentally driven notch surface degradation processes, the visco-plastic creep driven mechanisms which significantly change the notch root stresses were also considered.

The notch root max stresses were found to be significantly lower for the max dwell loading profile due to creep induced stress relaxation in comparison to the min dwell waveform. Slow cool heat treatment also produced lower max notch root stresses than the fast cooled heat treatment for the two dwell load profiles investigated.

These differences in the notch root stresses had a major effect on the lives of the tested NLCF specimens, especially when the environmentally driven notch surface degradation mechanisms became active. Thus for the lab air tests, the min dwell NCF lives were very short and were found for a majority of the test conditions to be considerably lower in comparison to the max dwell tests. This occurred despite a prevailing transgranular crack initiation process being active. Two different environmentally driven mechanisms were identified to be responsible for the early crack initiation and premature failure. Formation of highly localized oxide scale regions and break up of small carbide particles after they have reacted with oxygen, created brittle phases on the surfaces of the notch which led to early crack initiation due to the high cyclic notch root stresses. While these phases also exist in max dwell tests, significantly lower notch root stresses prevent early crack initiation in these phases. Vacuum testing produced significantly longer dwell NLCF lives, especially for the min dwell loading profile.

The cooling rate from the solutioning heat treatment was found to be an important factor governing the NLCF lives of max dwell tests. Fast cool heat treatment resulted in considerably shorter NLCF lives in comparison to the slow cooled specimens. Both the higher notch root stresses of the fast cooled specimens and possible changes to the grain boundary microstructure due to the fast cooling rate produced conditions which favored the observed intergranular crack initiation and lower NLCF lives.

\section{References}

1. T.P. Gabb, J. Telesman, L.J. Ghosn, A. Garg, J. Gayda, "Factors Influencing Dwell Fatigue Cracking in Notches of Powder Metallurgy Superalloys," NASA/TM-2011-217118, Washington, D.C., June, 2011.

2. M.R. Bache, J.P. Jones, G.L. Drew, M.C. Hardy, N. Fox, "Environment and time dependent effects on the fatigue response of an advanced nickel based superalloy," Int. J. of Fatigue, vol. 31, pp. 1719-1723, 2009.

3. D.F. Smith, E.F. Clatworthy, D.G. Tipton, W.L. Mankins, "Improving the Notch-Rupture Strength of Low-Expansion Superalloys," Superalloys 1980, ed. J.K. Tien et al., TMS, 1980, pp. 521-530.

4. R.H. Bricknell and D. Woodford, "The Embrittlement of Nickel Following High Temperature Air Exposure," Met. Trans. A, vol. 12, March 1981, pp. 425-433.

5. U. Krupp, P. Wagenhuber, W.M. Kane, T. Jacobs, C.J. McMahon Jr., "Environmentally Assisted Brittle Fracture of Nickel-Base Superalloy at High Temperatures," Proc. of the 11th Int. Congress of Fracture, Turin, Italy, 2005. 


\begin{tabular}{|c|c|c|c|c|c|}
\hline \multicolumn{5}{|c|}{ REPORT DOCUMENTATION PAGE } & $\begin{array}{l}\text { Form Approved } \\
\text { OMB No. 0704-0188 }\end{array}$ \\
\hline \multicolumn{6}{|c|}{ 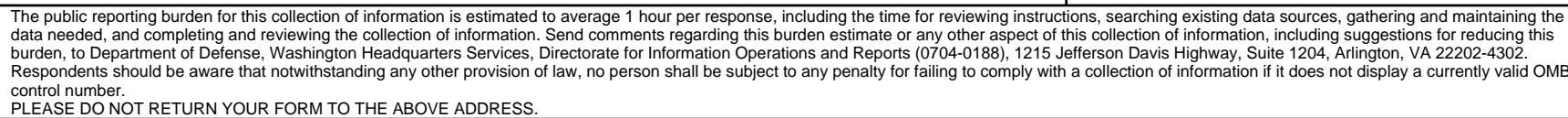 } \\
\hline \multicolumn{2}{|c|}{$\begin{array}{l}\text { 1. REPORT DATE (DD-MM-YYYY) } \\
01-12-2012\end{array}$} & \multicolumn{3}{|c|}{$\begin{array}{l}\text { 2. REPORT TYPE } \\
\text { Technical Memorandum }\end{array}$} & 3. DATES COVERED (From - To) \\
\hline \multirow{3}{*}{\multicolumn{5}{|c|}{$\begin{array}{l}\text { 4. TITLE AND SUBTITLE } \\
\text { Dwell Notch Low Cycle Fatigue Behavior of a Powder Metallurgy Nickel Disk Alloy }\end{array}$}} & 5a. CONTRACT NUMBER \\
\hline & & & & & 5b. GRANT NUMBER \\
\hline & & & & & 5c. PROGRAM ELEMENT NUMBER \\
\hline \multirow{3}{*}{\multicolumn{5}{|c|}{$\begin{array}{l}\text { 6. AUTHOR(S) } \\
\text { Telesman, J.; Gabb, T., P.; Yamada, Y.; Ghosn, L., J.; Hornbach, D.; Jayaraman, N. }\end{array}$}} & 5d. PROJECT NUMBER \\
\hline & & & & & 5e. TASK NUMBER \\
\hline & & & & & $\begin{array}{l}\text { 5f. WORK UNIT NUMBER } \\
\text { WBS 284848.02.04.03.03.03.01 }\end{array}$ \\
\hline \multicolumn{5}{|c|}{$\begin{array}{l}\text { 7. PERFORMING ORGANIZATION NAME(S) AND ADDRESS(ES) } \\
\text { National Aeronautics and Space Administration } \\
\text { John H. Glenn Research Center at Lewis Field } \\
\text { Cleveland, Ohio 44135-3191 }\end{array}$} & $\begin{array}{l}\text { 8. PERFORMING ORGANIZATION } \\
\text { REPORT NUMBER } \\
\text { E-18374 }\end{array}$ \\
\hline \multirow{2}{*}{\multicolumn{5}{|c|}{$\begin{array}{l}\text { 9. SPONSORING/MONITORING AGENCY NAME(S) AND ADDRESS(ES) } \\
\text { National Aeronautics and Space Administration } \\
\text { Washington, DC 20546-0001 }\end{array}$}} & $\begin{array}{l}\text { 10. SPONSORING/MONITOR'S } \\
\text { ACRONYM(S) } \\
\text { NASA }\end{array}$ \\
\hline & & & & & $\begin{array}{l}\text { 11. SPONSORING/MONITORING } \\
\text { REPORT NUMBER } \\
\text { NASA/TM-2012-217691 }\end{array}$ \\
\hline \multicolumn{6}{|c|}{$\begin{array}{l}\text { 12. DISTRIBUTION/AVAILABILITY STATEMENT } \\
\text { Unclassified-Unlimited } \\
\text { Subject Categories: } 07 \text { and } 26 \\
\text { Available electronically at http://www.sti.nasa.gov } \\
\text { This publication is available from the NASA Center for AeroSpace Information, 443-757-5802 }\end{array}$} \\
\hline \multicolumn{6}{|c|}{ 13. SUPPLEMENTARY NOTES } \\
\hline \multicolumn{6}{|c|}{$\begin{array}{l}\text { 14. ABSTRACT } \\
\text { A study was conducted to determine the processes which govern dwell notch low cycle fatigue (NLCF) behavior of a powder metallurgy } \\
\text { (P/M) ME3 disk superalloy. The emphasis was placed on the environmentally driven mechanisms which may embrittle the highly stressed } \\
\text { notch surface regions and reduce NLCF life. In conjunction with the environmentally driven notch surface degradation processes, the visco- } \\
\text { plastic driven mechanisms which can significantly change the notch root stresses were also considered. Dwell notch low cycle fatigue } \\
\text { testing was performed in air and vacuum on a ME3 P/M disk alloy specimens heat treated using either a fast or a slow cooling rate from the } \\
\text { solutioning treatment. It was shown that dwells at the minimum stress typically produced a greater life debit than the dwells applied at the } \\
\text { maximum stress, especially for the slow cooled heat treatment. Two different environmentally driven failure mechanisms were identified as } \\
\text { the root cause of early crack initiation in the min dwell tests. Both of these failure mechanisms produced mostly a transgranular crack } \\
\text { initiation failure mode and yet still resulted in low NLCF fatigue lives. The lack of stress relaxation during the min dwell tests produced } \\
\text { higher notch root stresses which caused early crack initiation and premature failure when combined with the environmentally driven surface } \\
\text { degradation mechanisms. The importance of environmental degradation mechanisms was further highlighted by vacuum dwell NLCF tests } \\
\text { which resulted in considerably longer NLCF lives, especially for the min dwell tests. }\end{array}$} \\
\hline \multicolumn{6}{|c|}{$\begin{array}{l}\text { 15. SUBJECT TERMS } \\
\text { Notch low cycle fatigue; Dwells; Oxidation; Vacuum; Alloy ME3 }\end{array}$} \\
\hline \multicolumn{3}{|c|}{ 16. SECURITY CLASSIFICATION OF: } & $\begin{array}{l}\text { 17. LIMITATION OF } \\
\text { ABSTRACT }\end{array}$ & $\begin{array}{l}\text { 18. NUMBER } \\
\text { OF }\end{array}$ & $\begin{array}{l}\text { 19a. NAME OF RESPONSIBLE PERSON } \\
\text { STI Help Desk (email:help@sti.nasa.gov) }\end{array}$ \\
\hline $\begin{array}{l}\text { a. REPORT } \\
\text { U }\end{array}$ & $\begin{array}{l}\text { b. ABSTRACT } \\
\text { U }\end{array}$ & $\begin{array}{l}\text { c. THIS } \\
\text { PAGE } \\
\text { U }\end{array}$ & UU & $\begin{array}{c}\text { PAGES } \\
18\end{array}$ & $\begin{array}{l}\text { 19b. TELEPHONE NUMBER (include area code) } \\
443-757-5802\end{array}$ \\
\hline
\end{tabular}



